\title{
Preparation and 0ptical Patterning of Organic-Inorganic Hybrid Color-Filter Films Using Latent Pigments by Utilizing Photo-Acid-Generator and Microwave Irradiation
}

\author{
T. Ohishi*, S. Sugawara \\ Department of Applied Chemistry, Faculty of Engineering, Shibaura Institute of Technology, \\ Tokyo, Japan \\ Email: ${ }^{*}$ tooishi@sic.shibaura-it.ac.jp
}

Received 7 October 2014; revised 29 October 2014; accepted 12 November 2014

Copyright (C) 2014 by authors and Scientific Research Publishing Inc.

This work is licensed under the Creative Commons Attribution International License (CC BY). http://creativecommons.org/licenses/by/4.0/

(c) (i) Open Access

\begin{abstract}
Preparation and photo-patterning characteristics of organic-inorganic hybrid thin film containing latent pigment by using photo-acid-generator (PAG) and microwave irradiation have been investigated. The acrylic thin film modified with methoxysilane containing PAG was formed on a glass substrate and irradiated with ultraviolet rays to promote sol-gel reaction by catalytic action of acid which was generated from PAG. And then the film was hardened with microwave irradiation, yielding organic-inorganic hybrid polymer film having hardness, highly transparency and strong adhesion with a glass substrate. Since this reaction only occurred in the optically (UV) irradiated regions, by exploiting the difference between the adhesivenesses of these regions photo-irradiated through photomask with a glass substrate, it was possible to form a patterned film with pitch of 100 to $50 \mu \mathrm{m}$ by a simple lift-off method. A pigment-containing film using latent pigments (with subtractive three primary colors of coloring materials) and a patterned film were prepared, and it was possible to make these films multi-colored by varying the mixing ratio of the pigments. This multi-colored film-preparation method is effective for simply and efficiently forming a color-filter film by applying optical and microwave irradiation.
\end{abstract}

\section{Keywords}

Organic-Inorganic Hybrid Film, Color Filter, Photo-Patterning, Latent Pigment,

\footnotetext{
${ }^{*}$ Corresponding author.
}

How to cite this paper: Ohishi, T. and Sugawara, S. (2014) Preparation and Optical Patterning of Organic-Inorganic Hybrid Color-Filter Films Using Latent Pigments by Utilizing Photo-Acid-Generator and Microwave Irradiation. Materials Sciences and Applications, 5, 1079-1090. http://dx.doi.org/10.4236/msa.2014.514111 


\section{Photo-Acid-Generator, Microwave, Lift-Off Method}

\section{Introduction}

In recent years, organic-inorganic hybrid films-which combine the flexibility and responsiveness of organic substances with the hardness of inorganic substances-are being applied in fields like integrated circuits and optical devices [1]-[10]. Among organic-inorganic hybrid films, those including functional organic dyes combine the expression of new optical properties with improvement in durability. Accordingly, it is expected that they will be applied in a wide range of fields_starting from recording elements and display devices [11]-[15]. Color filters for display devices are an important field in which these organic-inorganic hybrid films are being applied. Present mainstream color filters consist of an organic pigment dispersed in a photosensitive organic polymer [16]. However, degradation of their optical characteristics by the onset of agglomeration of the organic pigment in a solvent, low scratch resistance (derived from the organic polymer), and degradation of adhesion with the film's substrate are some of the common problems with these filters. Moreover, the process for manufacturing the color filter involves optical patterning by photolithography, which is beset by problems such as occurrence of liquid residue during post-light-exposure etching and shortening of film-hardening time [17] [18]. In light of the above-described problems, it is required to develop a new material for forming a color filter with higher performance and an easy-to-use optical-patterning method for manufacturing the filter.

The aim of the present study was to develop an easy-to-use optical patterning process and improve the optical characteristics and strength of a color-filter film. By doping a latent pigment into an organic-inorganic hybrid film by utilizing a siloxane-group-linked acrylic resin, a high-performance color-filter film with outstanding transparency, hardness, and durability (such as high adhesiveness) was prepared, and its properties were investigated. Furthermore, as an easy-to-use patterning approach, optical patterning based on a "lift-off" method and formation of a sol-gel film by using a photo-acid generator was investigated. As for an efficient method for curing the film, microwave irradiation was used instead of the conventionally used heat treatment.

As a method for optical patterning of the organic-inorganic hybrid film, irradiation by ultraviolet (UV) light onto a sol-gel film (composed of a chemically modified alkoxide) is known to be available. As for a film prepared by this method, variation of its solubility with regard to the solvent of the UV-irradiated gel film is exploited, and patterns in the film are formed by etching [19]-[23]. In this study, an easy-to-use optical patterning method-which uses a lift-off technique and does not generate solvent residue due to the etching-is applied.

\section{Experimental}

\subsection{Preparation of Latent Pigments}

Synthetic method of quinacridon (Qn) latent pigment is described below as an example.

Qn pigment $0.30 \mathrm{~g}$ (0.96 mmol), di-t-buthyl dicarbonate $0.83 \mathrm{~g}$ (3.80 mmol: t-BOC) and 4-dimethylaminopyridine $0.25 \mathrm{~g}$ (2.10 mmol: 4-DMAP) were mixed in N,N-dimethylformamide (70 ml: DMF). The mixed solution was stirred for 24 hours at room temperature. This solution was dropped into water, and the resulting precipitates were filtered and dried. Yellow precipitates were recrystallized from chloroholm and hexane to give Qn latent pigment (Qn-BOC). Yield: 0.190 g (39\%).

Indigo latent pigment (Indigo-BOC) and Pigment Yellow 93 latent pigment (PY-BOC) were prepared by a similar method to that of Qn-BOC.

\subsection{Preparation of PMPTMS}

Poly-methacryloxypropyltrimethoxysilane (PMPTMS) was synthesized by block polymerization.

3-methacry-loxypropyltrimethoxysilane (MPTMS) $2.96 \mathrm{~g}$ (11.9 mmol) and 1-Hydroxycyclohexylphenylketone (HCPK: Photo-polymerization initiator) $0.06 \mathrm{~g}(0.29 \mathrm{mmol})$ were mixed and stirred for 5 min at rotating speed $500 \mathrm{rpm}$. This solution was irradiated with ultraviolet ray (low pressure mercury lamp, emitting wavelength: $254 \mathrm{~nm}, 185 \mathrm{~nm}$, photo-intensity: $5 \mathrm{~mW} / \mathrm{cm}^{2}$ ) under nitrogen. After $30 \mathrm{~min}$., a stir bar stopped due to high viscosity of the solution because of polymerization. This polymer was diluted with THF and then poured 
into hexane. After standing in a refrigerator for 24 hours, white precipitate was decanted with hexane and filtered and dried in $\mathrm{N}_{2}$. Yield: $1.586 \mathrm{~g}$ (54\%).

\subsection{Thin Film Formation}

PMPTMS $20 \mathrm{wt} \%$, triphenylsulfoniumtriflate (PAG) $1.0 \%$ and $\mathrm{H}_{2} \mathrm{O}$ 0.5\% were dissolved in THF 58.5\%. And then cyclohexanone $20 \mathrm{wt} \%$ was added to this solution, resulting in the spin-coating solution for thin film formation. The solution was spin-coated on the glass substrate $(30 \times 30 \times 1.2 \mathrm{mmt})$ at rotating speed $3000 \mathrm{rpm}$ for $60 \mathrm{sec}$. to form the thin film. Photomask with $100 \mu \mathrm{m}$ or $50 \mu \mathrm{m}$ slit was attached on the film, following to be irradiated with ultraviolet ray using low pressure mercury lamp at photo intensity of $5.0 \mathrm{~mW} / \mathrm{cm}^{2}$ for $10 \mathrm{sec}$. After UV irradiation the film was peeled off by a lift-off method using scotch tape. And then the patterned film was irradiated with microwave (MW, $2.45 \mathrm{GHz}, 100 \mathrm{~W}$ ) for 5 to $10 \mathrm{~min}$. to harden the film.

\subsection{Thin Film Formation of PMPTMS Containing Latent Pigments}

Latent pigment Qn-BOC $0.70 \mathrm{wt} \%$ (Indigo-BOC $1.80 \mathrm{wt} \%$, PY-BOC $1.50 \mathrm{wt} \%$ ) was added to the PMPTMS solution for thin film formation described in 2.3, respectively. By using this solution PMPTMS thin films containing latent pigment were prepared in the same way to the formation method of PMPTMS thin film.

To make multi-coloring thin film the appropriate ratios of Qn-BOC:Indigo-BOC, Qn-BOC:PY-BOC and Indigo-BOC:PY-BOC were mixed and added to the coating solution. The multi-coloring thin films were prepared by using this solution.

\subsection{Evaluation}

Infrared spectroscopy (Shimadzu FT-IR 8400S) and ${ }^{1} \mathrm{H}$ nuclear magnetic resonance spectroscopy (JEOL FTNMR JNM-ECS400) were used to analyze the structure of latent pigments and organic-inorganic hybrid polymer (PMPTMS). Ultraviolet-Visible spectroscopy (Shimadzu UV2450) was measured to analyze a transparency and absorption characteristics of the films containing latent pigment. The positions of the films containing pigments on chromaticity coordinates were obtained from the values of absorption spectra. Surface morphology of the films was measured with optical microscope (Kyowakogyo ME-LUX2) and laser microscope (Keyence VK-X200). For the evaluation of hardness of the coating films, the dynamic hardness was measured with a dynamic ultra-microhardness tester (Shimadzu DUH 211S) and pencil hardness was evaluated by a tape test conforming to Japan Industrial Standard (JIS K5600).

\section{Results and Discussion}

\subsection{Fine Patterning Using Photo-Acid Generator and Organic-Inorganic-Hybrid Polymer}

An outline of the synthesis route for the organic-inorganic-hybrid polymer and formation of a fine pattern are shown in Figure 1 and Figure 2, respectively. As the starting material for the organic-inorganic-hybrid polymer, 3-methacryloxypropyltrimethoxysilane (MPTMS) was used. MPTMS consists of methacrylate organic regions and methoxysilane inorganic regions existing in a molecular framework. First, the organic regions are subjected to photo radical polymerization by UV irradiation. The $\mathrm{C}=\mathrm{C}$ bonds of the organic framework are cleaved by radical polymerization, and poly-MPTMS (PMPTMS) is synthesized with the progression of organic polymerization. Next, the methoxysilane regions are subjected to inorganic polymerization by a sol-gel reaction. After a photo-acid generator (PAG) is added to the solvent for forming the PMPTMS film, a film is formed on a glass substrate. When that film is irradiated with UV light, acid that catalyzes the sol-gel reaction is generated from the PAG in the film, and the sol-gel reaction progresses. Via the sol-gel reaction, methoxy groups are then inorganically polymerized and converted into siloxane bonds. Finally, a condensation reaction is initiated by MW irradiation, and the film is hardened. The organic-inorganic hybrid resin synthesized by this process consists of organic regions and inorganic regions within its molecular framework; consequently, it is expected that its compatibility with organic pigment will be improved by the organic constituents, resulting in high chromogenicity, and its durability will be high due to the inorganic constituents.

The chemical structure of the PAG used (triphenylsulfoniumtriflate) and the acid-generation mechanism are shown in Figure 3. The PAG generates acid only in the irradiated regions, so when the UV irradiation is limited 


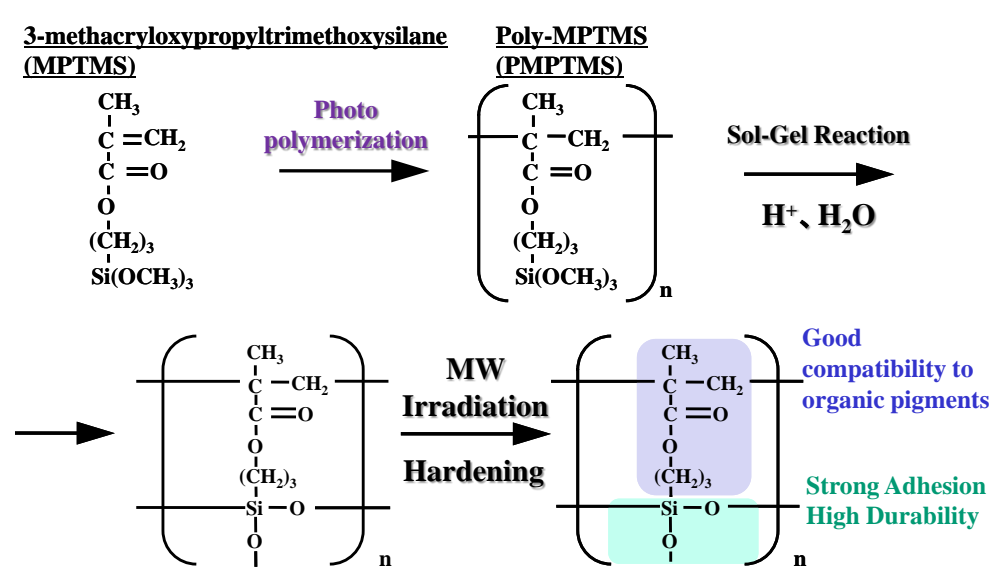

Figure 1. Preparation of photo-sensitive organic-inorganic hybrid polymer.

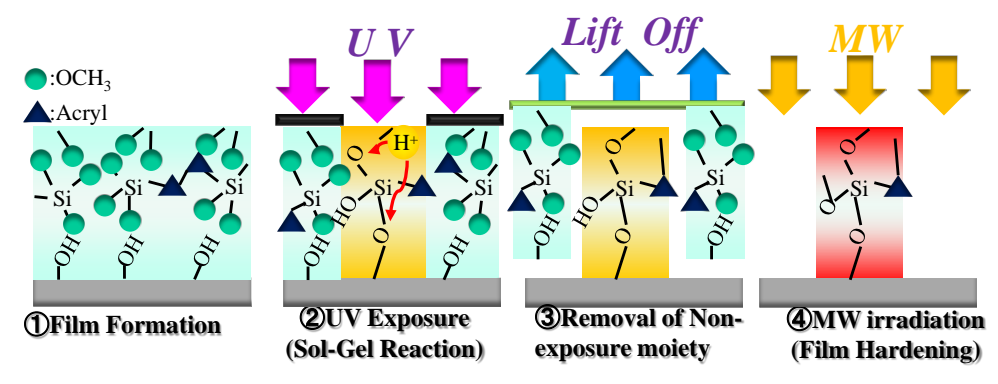

Figure 2. Schematic drawing of thin film patterning process using PAG.

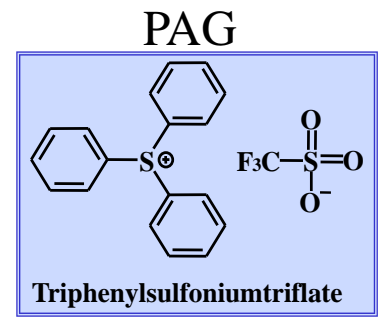

$$
\begin{aligned}
& \text { Mechanism of } \mathrm{H}^{+} \text {Generation } \\
& \text { 1) } \mathrm{S}^{+} \mathbf{P h}_{3} \stackrel{\text { hv }}{\longrightarrow} \mathrm{Ph}_{2} \mathrm{~S}^{+} \bullet+\mathbf{P h} \cdot \\
& \text { 2) } \mathrm{Ph}_{2} \mathrm{~S}^{+} \bullet \stackrel{\mathrm{R}-\mathrm{H}}{\longrightarrow} \mathrm{Ph}_{2} \mathrm{~S}^{+}-\mathrm{H}+\mathrm{R} \bullet \\
& \text { 3) } \mathrm{Ph}_{2} \mathrm{~S}^{+} \mathrm{H} \longrightarrow \mathrm{Ph}_{2} \mathrm{~S}+\mathrm{H}^{+} \\
& \text {Ph: } \mathrm{C}_{6} \mathrm{H}_{5} \text { R:Alkyl group }
\end{aligned}
$$

Figure 3. Chemical structure of photo acid generator (PAG) and mechanism of $\mathrm{H}^{+}$Generation.

through a photomask, the sol-gel reaction is promoted by the acid catalyst in the UV-irradiated regions only. As a result, as the inorganic polymerization proceeds, the $\mathrm{Si}-\mathrm{OH}$ groups of the glass surface react with the PMPTMS film, and chemical bonds are formed. The adhesiveness of the PMPTMS film with the glass substrate is thereby improved by this bonding. Exploiting the difference between the adhesiveness of the irradiated regions and that of the non-irradiated regions with the glass substrate makes it possible to form a fine patterning film by means of a simple lift-off method. The MWs (used instead of heat treatment for hardening the film) can act directly on the polarity of molecules in a different manner to heating by thermal convection and heat the interior of the film. As a result, a thin film can be heated efficiently, and processing time can be shortened.

\subsection{NMR and IR Spectra of Organic-Inorganic Hybrid Polymer}

Infrared spectra of MPTMS and photo-polymerized MPTMS (i.e., PMPTMS) are shown in Figure 4. MPTMS (namely, the starting material) shows stretching vibration of the $\mathrm{C}=\mathrm{C}$ bond derived from methacrylate of around $1600 \mathrm{~cm}^{-1}$, bending vibration of $-\mathrm{OCH}_{3}$ derived from the methoxy group of about $800 \mathrm{~cm}^{-1}$, stretching vibration of $\mathrm{C}-\mathrm{H}$ bond due to $-\mathrm{CH}_{2}$ - around $2950 \mathrm{~cm}^{-1}$, and stretching vibration of the $\mathrm{C}-\mathrm{H}$ bond due to $\mathrm{C}-\mathrm{CH}_{3}$ around 


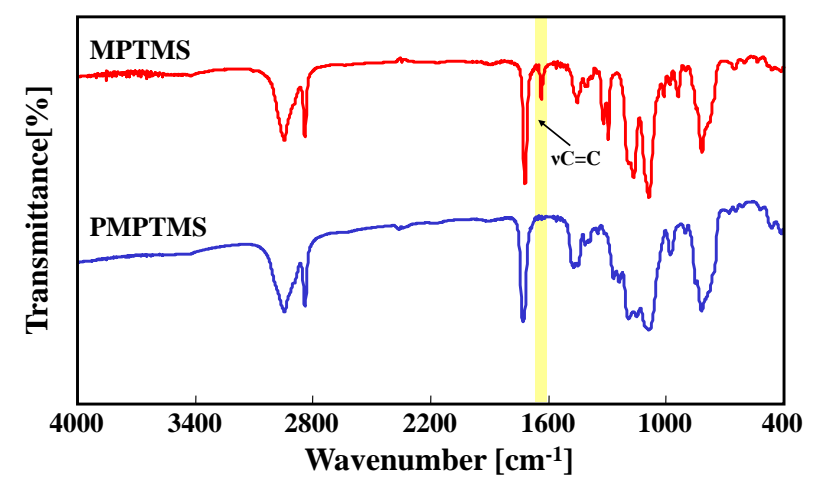

Figure 4. Infrared spectra of MPTMS and PMPTMS.

$2830 \mathrm{~cm}^{-1}$. As for photo-radical-polymerized MPTMS (i.e., PMPTMS), the stretching vibration of the $\mathrm{C}=\mathrm{C}$ bond has disappeared. This result confirms the polymerization of MPTMS.

${ }^{1} \mathrm{H}-\mathrm{NMR}$ spectra of PMPTMS (synthesized from MPTMS) and MPTMS are shown in Figure 5. MPTMS shows peaks ascribed to $\mathrm{C}=\mathrm{C}$-double-bond protons at $6.10 \mathrm{ppm}$ and $5.56 \mathrm{ppm},-\mathrm{CH}_{2}$ - protons adjoining a -COOgroup at $4.13 \mathrm{ppm},-\mathrm{OCH}_{3}$ protons at $3.58 \mathrm{ppm},-\mathrm{CH}_{3}$ protons at $1.95 \mathrm{ppm},-\mathrm{CH}_{2}$ - protons in the range 1.76 to $1.83 \mathrm{ppm}$, and silicon-adjoining $-\mathrm{CH}_{2}$ - protons in the range 0.68 to $0.72 \mathrm{ppm}$. Moreover, the integration ratio of hydrogen, namely, 1:1:2:9:3:2:2 (from the low-magnetic-field side), agrees with the proton number of MPTMS.

As for the ${ }^{1} \mathrm{H}-\mathrm{NMR}$ spectra of the synthesized PMPTMS, the peaks ascribed to the double-bond protons (at $6.10 \mathrm{ppm}$ and $5.56 \mathrm{ppm}$ ) have disappeared, inferring that the double bond has been cleaved. As for the integration ratio of proton number, the proton number of methoxy group with a peak at $3.58 \mathrm{ppm}$ is nine, while the integration ratio of the peaks at $0.65 \mathrm{ppm}, 1.73 \mathrm{ppm}$ and $3.90 \mathrm{ppm}$ is 2:2:2, indicating that these peaks are methylene group. That means the three peaks can be ascribed to the alkyl chains of the methacryloxy group. From the peak positions, it is inferred that the $0.65 \mathrm{ppm}$ is peak represents silicon-adjoining $-\mathrm{CH}_{2}$ - protons, $1.73 \mathrm{ppm}$ represents $-\mathrm{CH}_{2}$ - protons, and $3.90 \mathrm{ppm}$ represents $-\mathrm{CH}_{2}$ - protons adjoining a -COO-group. However, a weak peak at $1.10 \mathrm{ppm}$ can also be seen. Although it is likely to be an intermediate $-\mathrm{CH}_{2}$ - peak, its proton number does not agree. Moreover, as for PMMA (polymethylmethacrylate) synthesized from MMA (methylmethacrylate), after the $\mathrm{C}=\mathrm{C}$ (i.e., the main chain) bond is cleaved, the $-\mathrm{CH}_{2}$ - peak appears near $1.84 \mathrm{ppm}$ [24]. In the case of the synthesized PMPTMS as well, since a peak appears close to $1.85 \mathrm{ppm}$, it is inferred that it comes from the protons of the polymerized main chain of the PMPTMS.

The ${ }^{1} \mathrm{H}-\mathrm{NMR}$ peaks of the synthesized PMPTMS are similar to those of PMMA with a syndiotactic configuration [25]. Peaks also appear at $1.27 \mathrm{ppm}$ and $3.75 \mathrm{ppm}$, however. It is thus considered that the framework of PMPTMS is partly atactic. In light of that fact, in regard to the stereoregularity of PMPTMS, although it mainly involves a syndiotactic configuration, it also partly involves an atactic configuration.

\subsection{Optical Patterning of PMPTMS Film by Sol-Gel Process Using Photo-Acid Generator}

The state of a PMPTMS patterned thin film (width: $100 \mu \mathrm{m}$; no organic pigment) prepared by the proposed method is shown in Figure 6 by a) an optical-micrograph and b) 3D and cross-sectional laser micrographs of the pattern shape in the thickness direction of the film. The images show that an organic-inorganic hybrid film with a satisfactory pattern (with width of $100 \mu \mathrm{m}$ ) was formed and that the pattern is formed with an edge (with thickness of about $1 \mu \mathrm{m}$ ) cut perpendicularly into it.

In the optically irradiated regions, a condensation reaction between the $\mathrm{Si}-\mathrm{OH}$ group of the glass-substrate surface and the alkoxy group of the PMPTMS is promoted. As a result, adhesion of the film with the glass substrate by formation of chemical bonds becomes extremely strong. In the meantime, in the non-optically irradiated regions, inorganic polymerization does not proceed, chemical bonding with the glass substrate does not occur, and the adhesion with the glass substrate is weak. By exploiting this difference between the adhesivenesses of the respective regions with glass, it is conceivable that a lift-off method could be used for precise patterning. A lift-off method, which forms extremely simple patterns by "peeling off" a tape, does not produce liquid residue or need exclusive-use equipment in the manner of methods like etching; accordingly, it is a low-cost means of forming patterned films. 


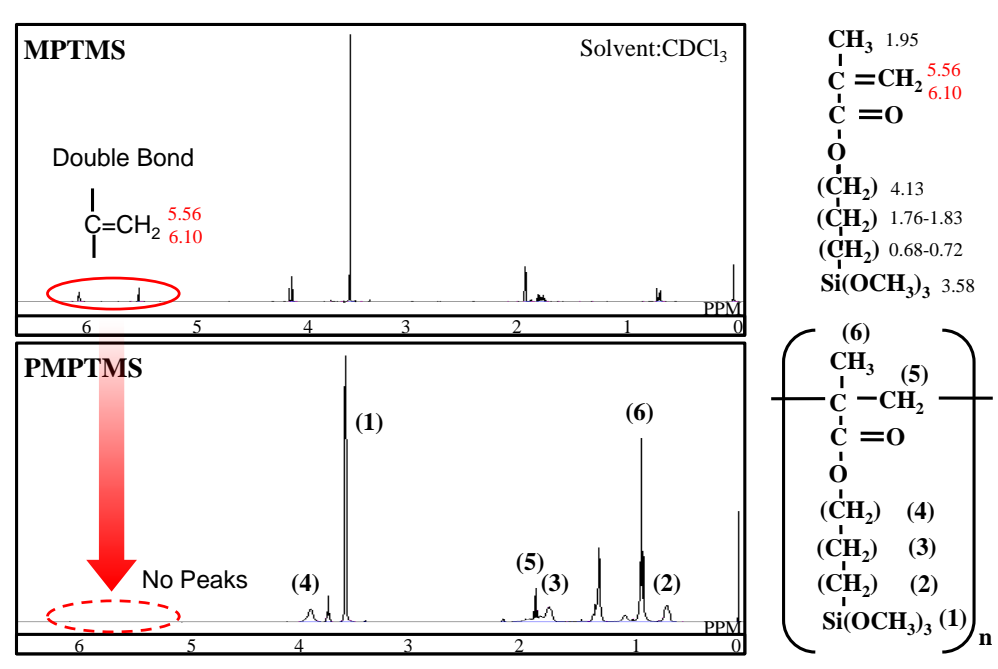

Figure 5. NMR spectra of MPTMS and PMPTMS.
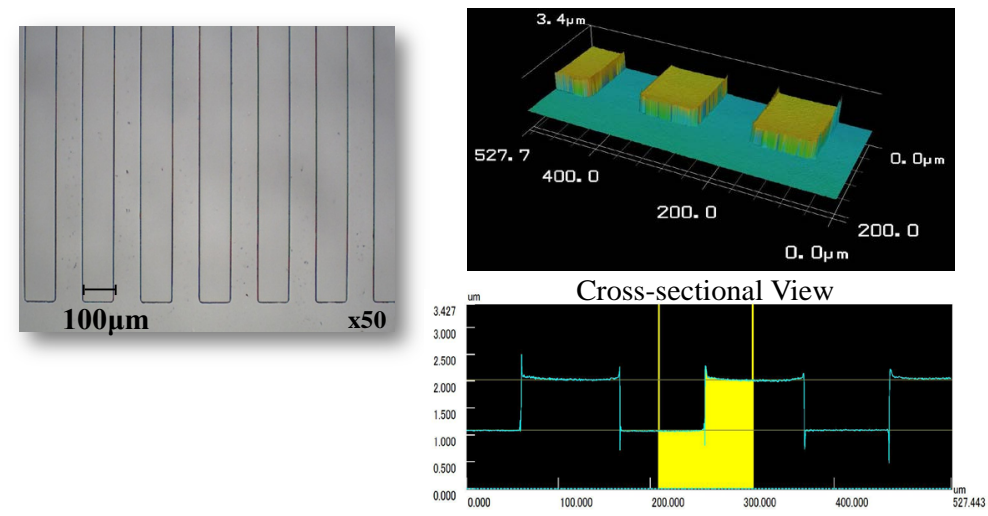

(a)

(b)

Figure 6. Surface photographs of patterned organic-inorganic hybrid thin film. (a) Optical microscope; (b) Laser microscope.

\subsection{Properties of PMPTMS Film}

The absorption spectrum of a thin film formed on glass substrate is shown in Figure 7. The transparency of the film is extremely high, indicating no absorption in the visible-light region $(380-800 \mathrm{~nm})$. In fact, it overlaps with the transmission line of the glass substrate. The measured hardness of the organic-inorganic hybrid thin film is plotted in Figure 8. The graph compares the PMPTMS film and an equivalent acrylic film (PMMA). It is clear that the pencil hardness of the hybrid film is considerably increased compared to that of the PMMA film (namely, from 6B to 4H). When the hardness of the thin films was measured by a thin-film microhardness tester, a significant difference between the films - in terms of the load behavior of the indenter under loading — was revealed. The load-displacement curves of the films (for a loading depth of $0.1 \mu \mathrm{m}$ ) are shown in Figure 8(b). The load on the PMMA film is lower than that on the PMPTMS film ( $0.15 \mathrm{mN}$ compared to $0.25 \mathrm{mN})$. Moreover, in contrast to the load behavior of the PMPTMS film (namely, the load-deformation line returns to the origin), that of the PMMA film shows that deformation damage remains (namely, the line does not return to the origin). While the PMPTMS film plastically deforms to a certain extent, it shows high elasticity during the loading-unloading process. The hardness of the PMPTMS film is significantly improved in comparison to that of the PMMA film; namely, the Martens' hardness (determined by loading-unloading test) of the former is 456.5 $\mathrm{N} / \mathrm{mm}^{2}$, and that of the latter is $258.6 \mathrm{~N} / \mathrm{mm}^{2}$. It is supposed that as a result of the sol-gel reaction (which is promoted by applying the photo-acid generator as previously described), siloxane bonds ( $\mathrm{Si}-\mathrm{O}-\mathrm{Si}$ ) are formed in the film, and a hard inorganic network is formed, and that hard-network formation explains the superior hard 


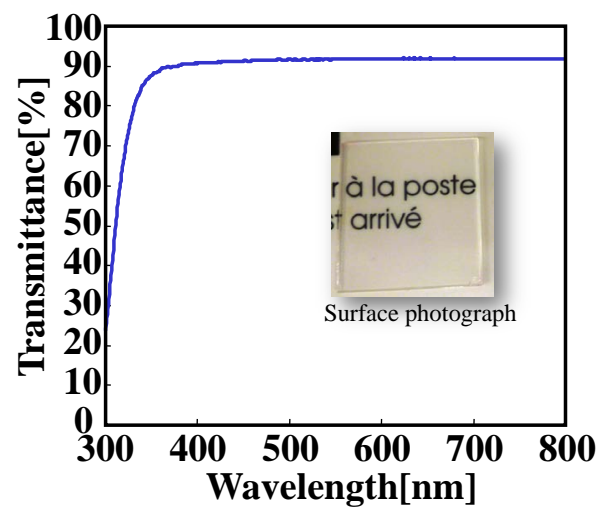

Figure 7. Absorption spectrum of organic-inorganic hybrid thin film on glass substrate.

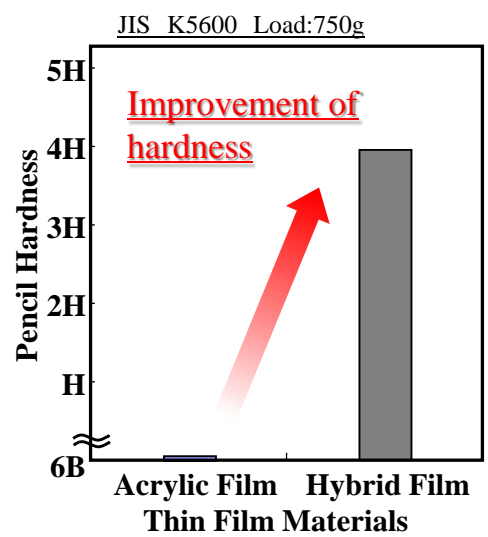

(a)

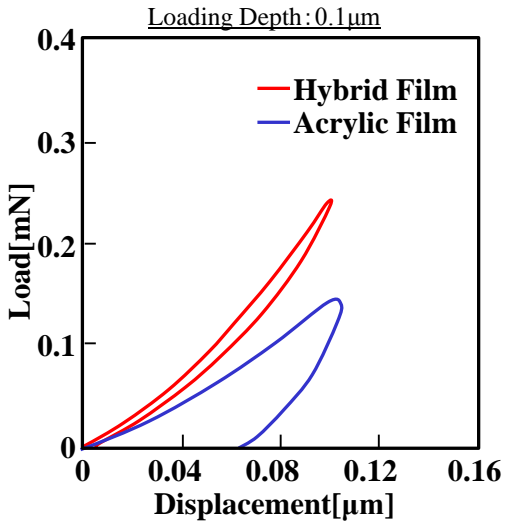

(b)

Figure 8. Hardness of organic-inorganic hybrid thin film. (a) Pencil test; (b) Microhardness.

ness of the PMPTMS film. Cross-cut adhesion test (ISO Cross-cut Test) was carried out to evaluate adhesiveness of PMPTMS film on a glass substrate. PMPTMS film showed the value of 25/25 (the number of residual films/the number of cross-cut films), indicating strong adhesiveness. In stark contrast, for acrylic film, which has been used for color filter, both the MW-irradiated film and the heat-treated film at $150^{\circ} \mathrm{C}$ showed the values of 0/25, indicating weak adhesiveness. The strong adhesiveness of PMPTMS film would be attributed to the chemical bonding between PMPTMS film and a glass substrate.

\subsection{Preparation of PMPTMS Film Containing Latent Pigments}

"Multi-coloring" by mixing coloring materials, namely, latent pigments (with three "primary colors" of subtractive mixture) into the synthesized PMPTMS film was investigated. The latent pigments used to form the three subtractive primary colors were cyan (i.e., indigo), yellow (i.e., PY93), and magenta (i.e., quinacridone)). The chemical structures of the pigments are shown in Figure 9. The latent pigments are compounds in which the hydrogen of the $\mathrm{N}-\mathrm{H}$ group in the pigment molecules is substituted by t-BOC $\left(\left(\mathrm{CH}_{3}\right)_{3} \mathrm{COCO}\right)$ groups, and they are soluble in a solvent by means of blocking hydrogen bonding between the pigment molecules [26]. The latent pigments are soluble in various solvents, and they can dissolve in solutions used for forming films. Moreover, as a result of converting them to pigments in which t-BOC groups introduced by heating are eliminated, it is possible to precipitate extremely small, uniform pigment particles in the film. It is thus possible to prepare a color film with excellent optical characteristics.

Changes in the surface color of latent-pigment-containing films (prepared on a glass substrate) after MW irradiation (500 W for $10 \mathrm{~min}$ ) or heat treatment are compared in Figure 10. After MW irradiation, it is clear that 


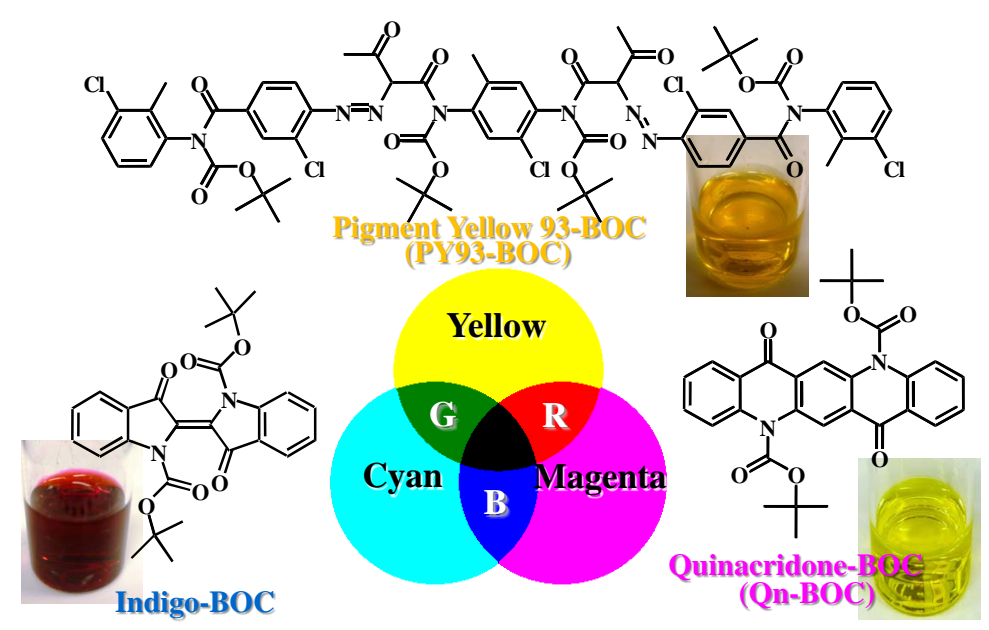

Figure 9. Chemical structure of latent pigments of subtractive three primary colors.

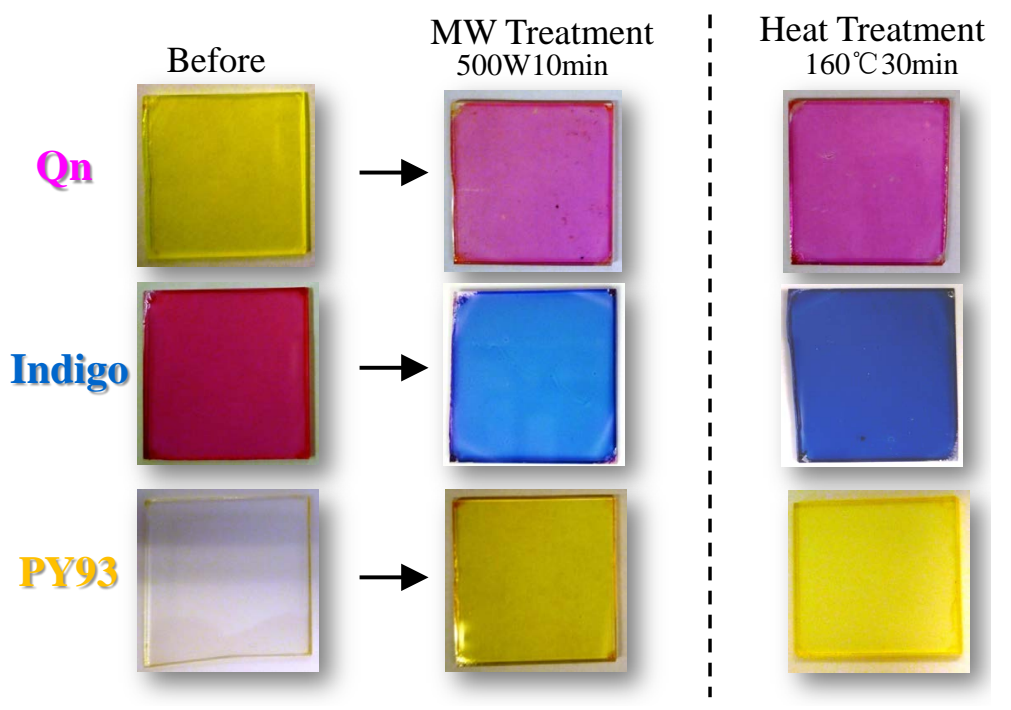

Figure 10. Changes of surface color after MW treatment or heat treatment.

the film produces the three subtractive "primary colors" of the coloring materials (magenta, cyan, and yellow). As for the heat-treated film, heating at $180^{\circ} \mathrm{C}$ for $30 \mathrm{~min}$ is necessary. The latent pigment is transformed by the MW irradiation (500 W for 5 to $10 \mathrm{~min}$ ) to active pigment, and a pigment-containing film is formed efficiently by MW irradiation. While hardening the PMPTMS film, the MW irradiation also contributes to forming active pigment from the latent pigment. Moreover, by varying the blend ratio of the latent pigments with the three subtractive "primary colors," it is possible to produce the three primary colors of light (namely, red, green, and blue) by subtractive mixture. Photographs of the surfaces of films with systematically varied color mixtures of latent pigments are shown in Figure 11. It can be clearly seen that just about all colors were successfully produced; in other words, a technique of colorization by applying latent pigments is feasible. The positions of the chromaticity coordinates of the prepared films are shown in Figure 12. The coordinates of the film showing the three primary colors of light mostly coincide with the $\mathrm{a}^{*}$ and $\mathrm{b}^{*}$ axes of the chromaticity-coordinate system, indicating that it properly expresses red, green, and blue.

Changes in absorption spectra when the mixing ratio of latent pigments is changed are shown in Figure 13. When the mixing ratios of the pigment mixtures (namely, indigo and Qn, PY93 and indigo, and Qn and PY93) are changed, absorption spectra with isosbestic points are obtained. This result shows that the two constituents are uniformly mixed in the films. Patterned films (prepared by the proposed method) containing the pigments 


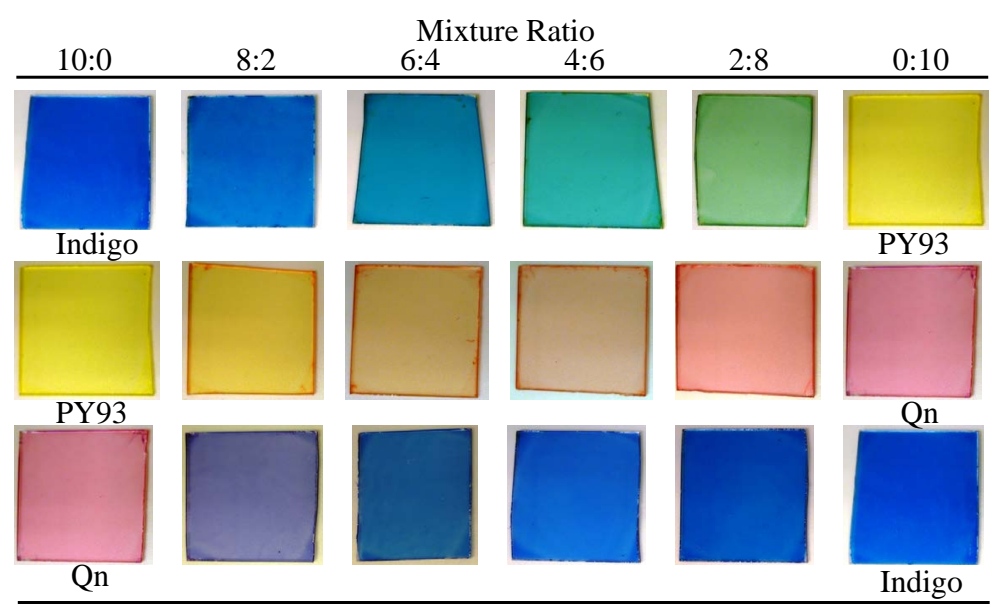

Figure 11. Surface photographs of color mixture films of latent pigments.

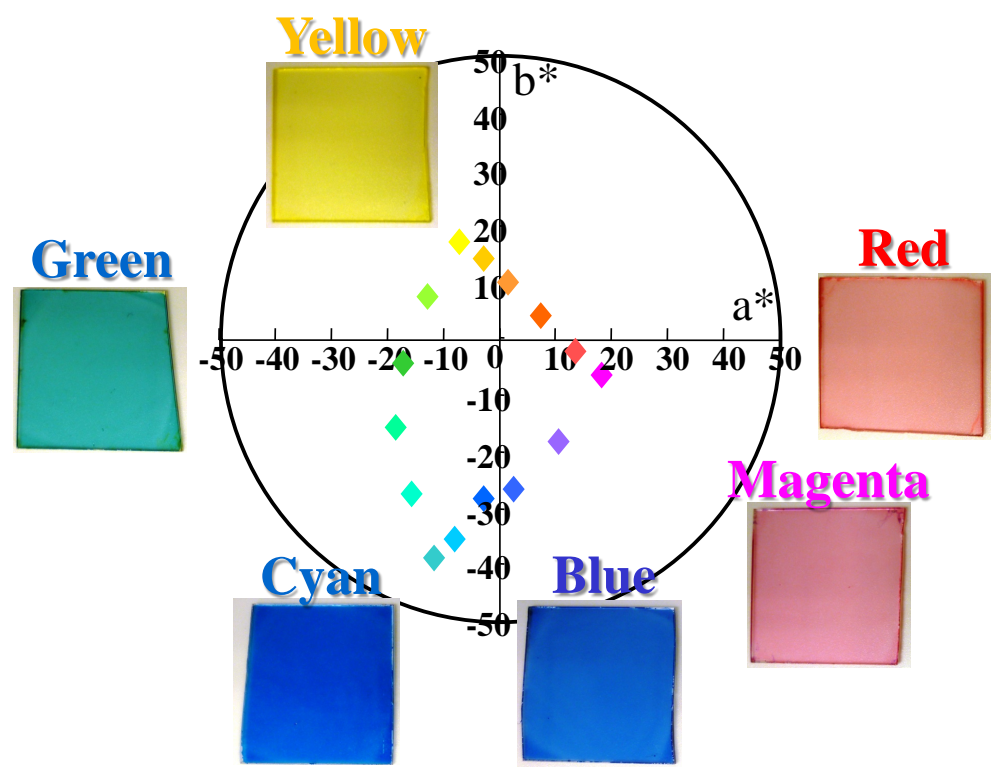

Figure 12. Chromaticity coordinates of the films prepared by using latent pigments.

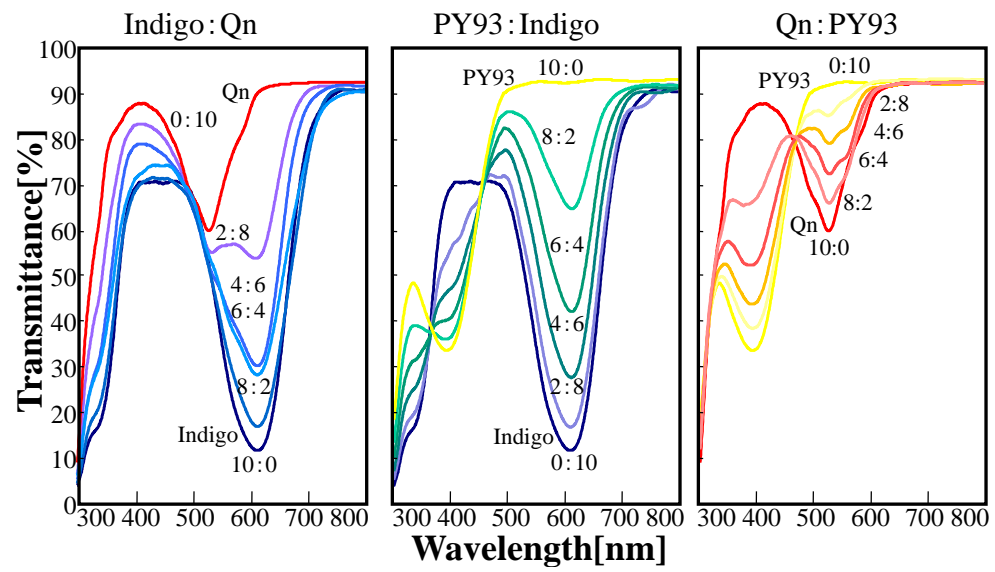

Figure 13. Absorption spectra of color mixture films of latent pigments. 
with the three subtractive primary colors of the coloring materials are shown in Figure 14. The photographs clearly show fine patterns with widths of $50 \mu \mathrm{m}$ and $100 \mu \mathrm{m}$ were uniformly formed. Optical micrographs and laser-microscope photographs of a 100- $\mu \mathrm{m}$ patterned film containing Qn pigment are shown in Figure 15. The images show that in the case of the film containing pigment, a satisfactory pattern is formed, and the edges of the patterns are cut precisely. Compared to the PMPTMS film without pigment, the film with pigment is thicker (about $2.3 \mu \mathrm{m}$ ). It is presumed that this additional thickness is due to the inclusion of particles of organic pigments in the film. Furthermore, the pencil hardness and adhesiveness of the film including pigments equal that (namely, pencil hardness 4H, cross-cut test 25/25) of PMPTMS without organic pigments. The other pigmentcontaining films (namely, the ones containing indigo and PY93) gave similar results. The developed PMPTMS film has high hardness and strong adhesiveness, indicating that the film would be applicable to color filter for displays. And microwave irradiation process is useful to harden the film and shorten processing time (5 - $10 \mathrm{~min}$ ) in comparison with conventional heat-treatment process (30 - $60 \mathrm{~min})$.

\section{Conclusion}

An organic-inorganic hybrid film containing latent pigments was prepared by using a photo-acid generator and

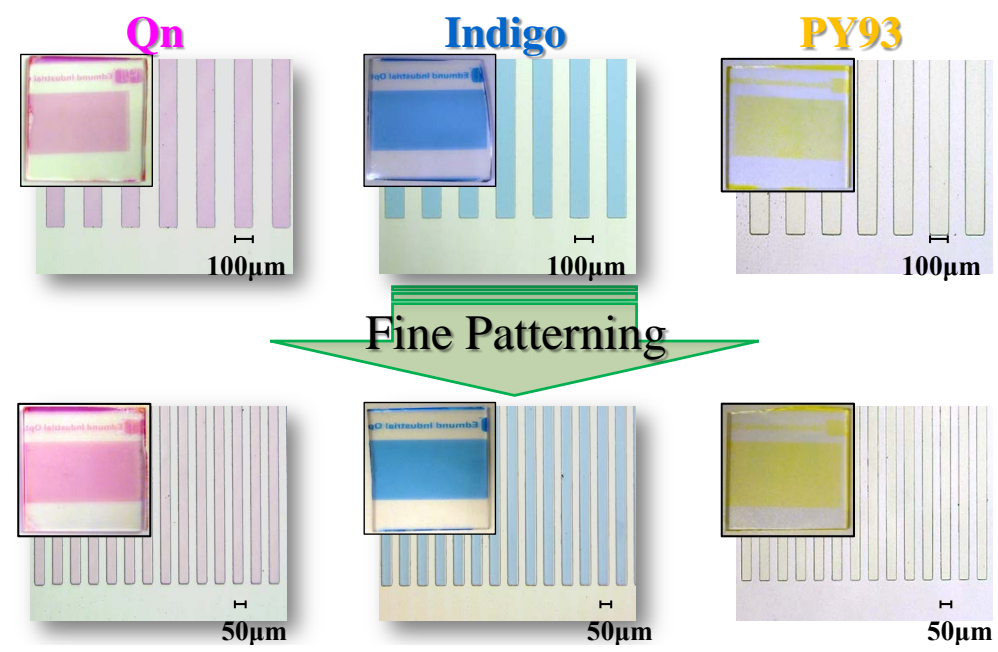

Figure 14. Surface photographs of fine patterned films containing three subtractive primary color pigments.

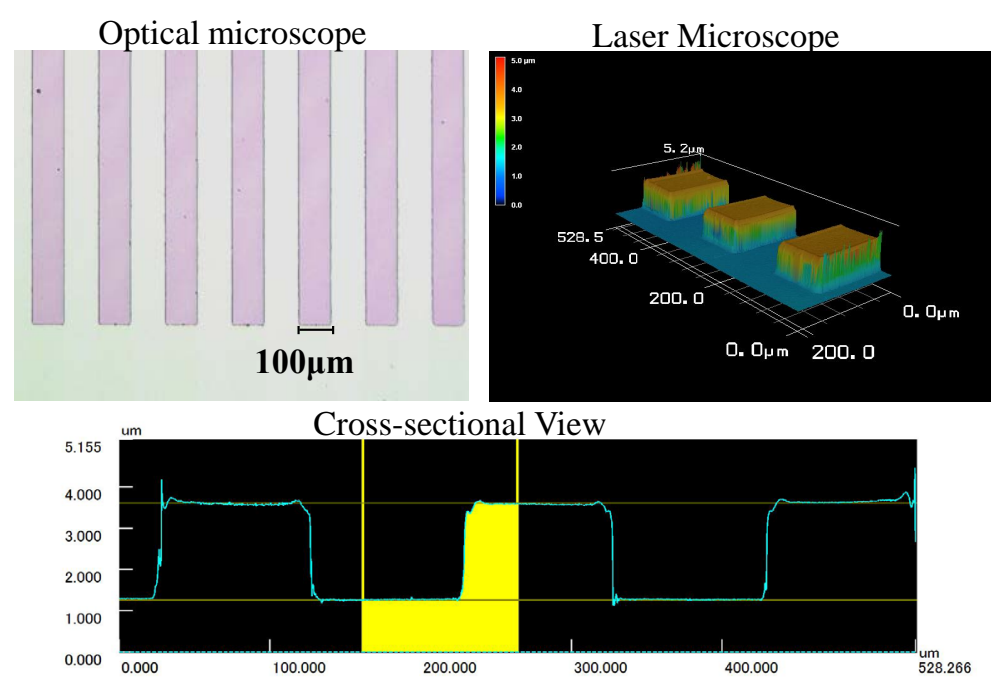

Figure 15. Surface photographs of $100 \mu \mathrm{m}$ patterned film containing Qn Pigment. 
MW irradiation and optically patterned by UV light. Acrylic resin combining methoxysilane groups forms a hard and highly transparent thin film as a result of a sol-gel reaction being promoted by an acid generated by a photo-acid generator. Since this reaction only occurs in the optically (UV) irradiated regions, by exploiting the difference between the adhesivenesses of these regions with a glass substrate, it is possible to form a patterned film with pitch of 100 to $50 \mu \mathrm{m}$ by a simple lift-off method. Moreover, a pigment-containing film using latent pigments (with three primary colors of coloring materials) and a patterned film were prepared, and it was possible to make these films multi-colored by varying the mixing ratio of the pigments. This multi-colored film-preparation method is effective for simply and efficiently forming a color-filter film by applying optical and MW irradiation.

\section{References}

[1] Sakka, S., Ed. (2004) Handbook of Sol-Gel Technology, Sol-Gel Processing. Vol. 1, Kluwer Anademic Publishers, Dordrecht.

[2] Sakka, S., Ed. (2004) Handbook of Sol-Gel Technology, Application of Sol-Gel Technology. Vol. 3, Kluwer Anademic Publishers, Dordrecht.

[3] Sakka, S., Ed. (2005) Application of Sol-Gel Processing to Nanotechnology. CMC Publishers.

[4] Schmidt, H., Jonscher, G., Goedicke, S. and Mennig, M. (2000) Sol-Gel Process as a Basic Technology of Nanoparticle-Dispersed Inorganic-Organic Composites. Journal of Sol-Gel Science and Technology, 19, 39. http://dx.doi.org/10.1023/A:1008706003996

[5] Bescher, E. and Mackenzie, J.D. (2003) Sol-Gel Coatings for the Protection of Brass and Bronze. Journal of Sol-Gel Science and Technology, 26, 1223.

[6] Ro, H.W. and Soles, C.L. (2011) Mater. Today, Silsesquioxanes in Nanoscale Patterning Applications, 14, 20.

[7] Cordes, D.B., Lickiss, P.D. and Rataboul, F. (2010) Recent Developments in the Chemistry of Cubic Polyhedral Oligosilsesquioxane. Chemical Reviews, 110, 2081. http://dx.doi.org/10.1021/cr900201r

[8] Ainuddin, A.R., Hakiri, N., Muto, H., Sakai, M. and Matsuda, A. (2011) Mechanical Properties of Phenylsilsesquioxane-Methylsilsesquioxane Hybrid Films by Indentation. Journal of the Ceramic Society of Japan, 119, 490. http://dx.doi.org/10.2109/jcersj2.119.490

[9] Matsuda, A., Ogawa, R., Daiko, Y., Tadanaga, K. and Tatsumisago, A. (2007) Micropatterning for Vinylsilsesquioxane-Titania hybrid Gel Films with Ultraviolet Light Irradiation. Journal of Photopolymer Science and Technology, 20, 101. http://dx.doi.org/10.2494/photopolymer.20.101

[10] Ainuddin, A.R., Ishigaki, T., Hakiri, N., Muto, H., Sakai, M. and Matsuda, A. (2012) Influence of UV Irradiation on Mechanical Properties and Structures of Sol-Gel-Derived Vinylsilsesquioxane Films. Journal of the Ceramic Society of Japan, 120, 442. http://dx.doi.org/10.2109/jcersj2.120.442

[11] Nakazumi, H., Ed. (2004) Displays and Functional Dyes. CMC Publishers.

[12] Nonomura, K., Higashino, H. and Murai, R. (2002) Plasma Display Materials. MRS Bulletin, 27, 898-902. http://dx.doi.org/10.1557/mrs2002.280

[13] Okamura, T., Kitagawa, T., Koike, K. and Fukuda, S. (2004) Optical Filters for Plasma-Display Panels Using Organic Dyes and Conductive Meshlayers by Using a Roll-to-Roll Etching Process. Proceedings of the 8th Asian Symposium on Information Display, Nanjing, 15-17 February 2004, 23.

[14] Yang, Y.C., Song, K., Rho, S.G., Rho, N.S., Hong, S.J., Beul, K.B., Hong, M. and Chung, K. (2005) Society of Information Display (SID) '05 Digest, 1210.

[15] Minato, K., Itoi, T. and Ito, H. (2005) High Contrast Color Filter for LCD-TV. Proceedings of Information Display Workshop (IDW) ’05, 339.

[16] Nakazumi, H., Ed. (2004) Displays and Functional Dyes. CMC.

[17] Hatajima, M. (2007) NIKKEI FPD, 126.

[18] Masuda, J. (2008) Monthly Display, 9, 18.

[19] Shinmou, K., Tohge, N. and Minami, T. (1994) Effects of UV-Irradiation on the Formation of Oxide Thin Films from Chemically Modified Metal-Alkoxides. Journal of Sol-Gel Science and Technology, 2, 581-585.

[20] Zhao, G., Tohge, N. and Nishii, J. (1998) Fabrication and Characterization of Diffraction Gratings Using Photosensitive $\mathrm{Al}_{2} \mathrm{O}_{3}$ Gel Films. Japanese Journal of Applied Physics, 37, 1842-1846. http://dx.doi.org/10.1143/JJAP.37.1842

[21] Ono, S. and Hirano, S. (1997) Patterning of Lithium Niobate Thin Films Derived from Aqueous Solution. Journal of the American Ceramic Society, 80, 2533-2540. http://dx.doi.org/10.1111/j.1151-2916.1997.tb03155.x 
[22] Tadanaga, K., Owan, T., Morionaga, J., Urbanek, S. and Minami, T. (2000) Fine Patterning of Transparent, Conductive $\mathrm{SnO}_{2}$ Thin Films by UV-Irradiation. Journal of Sol-Gel Science and Technology, 19, 791-794. http://dx.doi.org/10.1023/A:1008764217509

[23] Tadanaga, K., Ueyama, K., Sueki, T., Matsuda, A. and Minami, T. (2003) Micropatterning of Inorganic-Organic Hybrid Coating Films from Various Trifunctional Silicon Alkoxides with a Double Bond in Their Organic Components. Journal of Sol-Gel Science and Technology, 26, 431-434. http://dx.doi.org/10.1023/A:1020745820563

[24] Higashimura, T., et al. (2007) Introduction to New Polymer Chemistry. Kagaku Doujin, Tokyo.

[25] NIMS NMR Database. http://polymer.nims.go.jo/NMR/

[26] Zambounis, Z., Hao, H. and Iqbal, A. (1997) Latent Pigments Activated by Heat. Nature, 388, 131-132. 
Scientific Research Publishing (SCIRP) is one of the largest Open Access journal publishers. It is currently publishing more than 200 open access, online, peer-reviewed journals covering a wide range of academic disciplines. SCIRP serves the worldwide academic communities and contributes to the progress and application of science with its publication.

Other selected journals from SCIRP are listed as below. Submit your manuscript to us via either submit@scirp.org or Online Submission Portal.
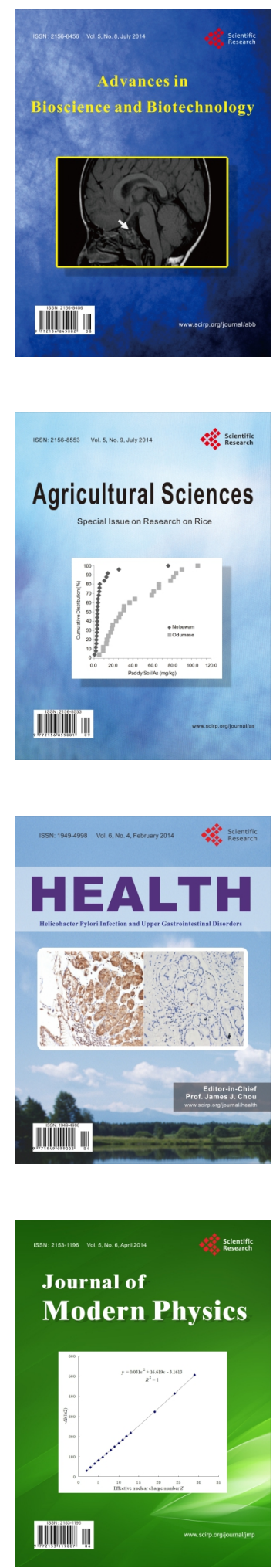
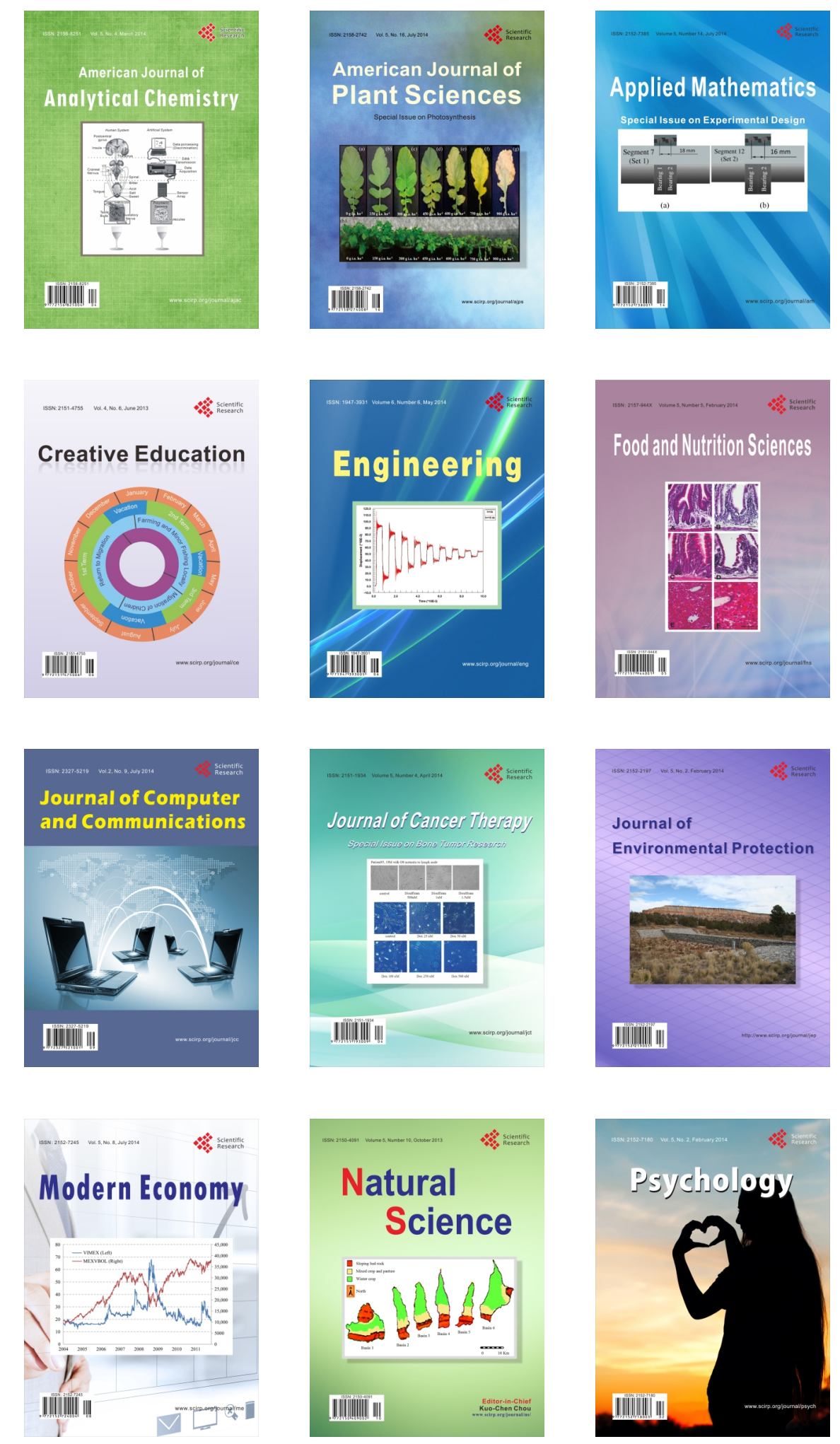